the posterior aspect of the left atrium, and it is proposed that this may have adversely affected atrio-ventricular conduction.

Bronchogenic cyst diagnosis is often made by a plain chest radiograph. Ultrasonography is useful to establish the cystic nature of a mass but CT scanning is superior, affording a

1 Rogers LF, Osmer JC. Bronchogenic cysts: a review of 46 cases. AfR 1964; 91: 273-83.

2 Salyer DC, Salyer WR, Eggleston JC. Benign developmental cysts of the mediastinum. Arch Pathol Lab Med 1977; tal cysts of $136-9$.

3 101: 136-9. Surg 1948; 127: 476 .

Surg 1948; 127: 476.
4 Holesh S. Mediastinal tumours. In: Shanks SC, Kerley PHK, eds $A$ textbook of $X$-ray diagnosis by British authors. 4th edn. London: Lewis, 1973. reasonably confident pre-operative diagnosis of type 1 or 2 cystic adenomatous malformations. Type 3 lesions, being more solid, are less confidently diagnosed before surgery. Magnetic resonance imaging is useful to define intraspinal involvement in association with a mediastinal mass. ${ }^{7}$

5 DiLorenzo M, Collin PPC, Vaillancourt R, Duranceau A Bronchogenic cysts. $\mathcal{F}$ Pediatr Surg 1989; 24: 988-91.

6 Reed JC, Sobonya RE. Morphological analysis of foregut cysts in the thorax. $A \mathscr{F} R$ 1973; 120: 851-60.

7 Haddon MJ, Bowen A. Bronchopulmonary and
7 A. 7 Haddon $M J$, Bowen $A$. Bronchopulmonary and nosis and management. Radiol Clin N Am 1991;29: 241-54.

\title{
Surgical cure of hypertension in a patient with brainstem capillary haemangioblastoma containing neuropeptide $\mathrm{Y}$
}

\author{
SA Hedderwick, AE Bishop, AJ Strong, JM Ritter
}

\begin{abstract}
Summary
We describe a 29-year-old woman with persistent arterial hypertension which resolved following complete excision of a capillary haemangioblastoma from within the spinal cord at the cervicomedullary junction. Immunohistochemical staining was positive for neuropeptide $Y$ in capillary walls and nerves in the tumour. This raises the possibility of an association between neuropeptide $Y$ and the central control of blood pressure in man.
\end{abstract}

Keywords: hypertension, neuropeptide Y, haemangioblastoma, surgery

macology,

UMDS, Medical

School Building, Guy's

Hospital, London SE1

9RT, UK

SA Hedderwick

JM Ritter

\section{Department of}

Histochemistry, Royal

Postgraduate Medical

School, Hammersmith

Hospital, London

W12 ONN, UK

AE Bishop

\section{Department of}

Neurosurgery, The

Maudsley Hospital,

London SE5 8AZ, UK

AJ Strong

Correspondence to

Professor JM Ritter

Accepted 9 December 1994
A 29-year-old Jamaican woman presented to casualty after a head injury, complaining of right facial numbness and weakness, intermittent slurred speech and drooling of saliva. There was a three-month history of sweaty episodes which were not associated with anxiety or palpitations. Arterial blood pressure was $200 / 105 \mathrm{mmHg}$ sitting. There was no previous history of hypertension with the exception of a single reading of $139 / 100 \mathrm{mmHg}$ in her first and only pregnancy two years earlier. Her mother had been diagnosed as having essential hypertension aged 54 . On examination she had pyramidal weakness and loss of sensation in the right arm with abnormal sensation over the right side of her face. Supine hypertension (130-200/100-126 mmHg) with a marked postural drop in blood pressure (of up to $80 \mathrm{mmHg}$ ) on standing but with no change in pulse rate, was a consistent finding during subsequent hospital admission. The remainder of the examination was normal. Initial investigations revealed a neutrophil leucocytosis (total white cell count $16.2 \times 10^{9} / 1$ ) and a urinary tract infection due to Proteus spp. The following were normal or negative: serum creatinine and electrolytes, liver function, glucose, syphilis serology, urinary vanilyl mandelic acid to creatinine ratio on two occasions, renal ultrasound. Cerebrospinal fluid examination was acellular with a raised protein $(1383 \mathrm{mg} / 1$, normal range $<450 \mathrm{mg} / \mathrm{l})$. Autonomic function tests were normal with the exception of supine hypertension and postural blood pressure fall without a significant pulse rise. Magnetic resonance imaging (MRI) showed an enhancing lesion adjacent to the posterior arch of $\mathrm{Cl}$ extending down to the 


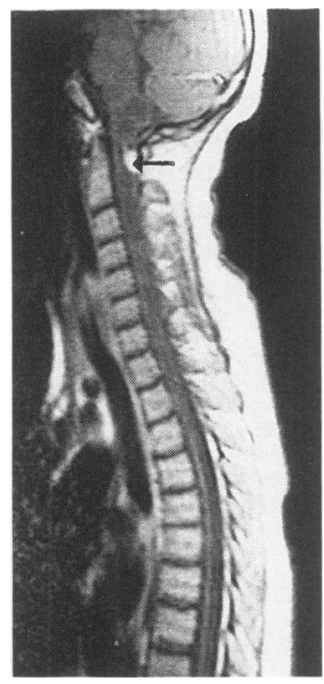

Figure 1 Gadoliniumenhanced $T-1$ weighted sagittal image showing an enhancing nodule anterior to the posterior arch of $\mathrm{Cl}$ (arrow) with evidence of cyst formation in the medulla and a cyst extending inferiorly through the cervical region

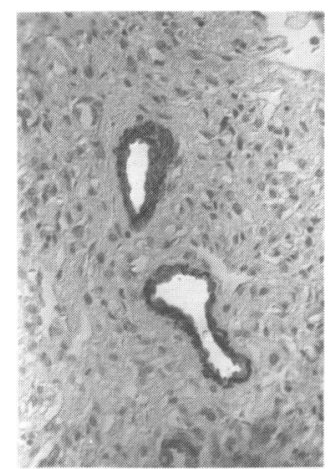

Figure 2 Section of a haemangioblastoma immunostained for neuropeptide Y. Dense immunoreactivity can be seen in the wall of blood vessels (avidin-biotin-peroxidase complex method with haematoxylin counterstain $\times 200$ ) interspace between $\mathrm{C} 1$ and $\mathrm{C} 2$ (figure 1), with a cystic area in the upper cervical cord extending into the medulla. The blood pressure was initially managed with nifedipine retard but supine hypertension (140-160 $\mathrm{mmHg}$ systolic pressure) and postural hypotension persisted. Oxprenolol $80 \mathrm{mg}$ twice daily was added and the blood pressure improved (130-160/ 90-100 $\mathrm{mmHg}$ ). A capillary haemangioblastoma was completely excised from within the cord at the cervico-medullary junction. Immuno-histochemical staining was negative for nitric oxide synthase (inducible, endothelial and neural isoforms), endothelin and vasoactive intestinal polypeptide, but positive for neuropeptide $Y$ in capillary walls (figure 2 ) and nerves. Post-operatively, she became normotensive off all medication and two months after discharge ambulatory blood pressure recording (Accutracker II, Suntech Medical Instruments) showed an average blood pressure of $123 / 84 \mathrm{mmHg}$.

\section{Discussion}

Anatomical data regarding the organisation of cardiovascular centres in man are scarce. Langford reported two cases of hypertension developing in young patients following removal of an angioblastoma from the floor of the fourth ventricle in the region of the obex. ${ }^{5}$ The second case demonstrated supine hypertension with a significant postural blood pressure drop. Our patient had a haemangioblastoma removed from the caudal part of her medulla and postural symptoms made her blood pressure difficult to control preoperatively. It is possible that raised blood pressure in each case was caused by damage to the nucleus tractus solitarius since hypertension can be produced in rats and cats by electrolytic lesions of this nucleus. ${ }^{6,7}$

In contrast to Langford's cases, our patient's blood pressure was normalised by complete excision of the tumour from the medulla. A similar cure of hypertension by surgery has not been reported previously and in animal models, damage to the brainstem has produced hypertension. ${ }^{6,7}$

The neurotransmitter neuropeptide $\mathrm{Y}$ is widely distributed in rat and in human brains
1 Dickinson CJ. Neurogenic hypertension. Andover: Chapman and Hall Medical, 1991.

2 Chronwall BM, Dimaggio DA, Massari VJ, Pickel DA, Ruggiero DA, O'Donohue TL. The anatomy of neuropep15: $1159-81$.

3 Adrian TE, Allen JM, Bloom SR, et al. Neuropeptide Y

distribution in human brain. Nature 1983; 306: 584-6.

Martin JR, Beinfeld MC, Westfall TC. Blood pressure
Matrion Martin JR, Beinfeld MC, Westfall TC. Blood pressure increases after injection of neuropeptide $Y$ into posterior
hypothalamic nucleus. Am $\subsetneq$ Physiol 1988; 254: H879-88. hypothalamic nucleus. Am f Physiol 1988; 254: H879-88.
Langford HG, Sandford R, Smith R, et al. Neurogenic hypertension in man: Reis, Barman-Gebber or Carey Syndrome. F Hypertension 1987; 5 (suppl 5): S467-9.

6 Doba N, Reis D. Acute fulminating neurogenic hypertension produced by brainstem lesions in the rat. Circulat Res 1973; 32: 584-93.

\section{Learning points: neuropeptide $Y$}

- 36 amino acid vasoconstrictor peptide, rich in tyrosine ( $\mathrm{Y}=$ tyrosine)

- isolated from brain, 1982

- widely distributed in central and peripheral nervous systems

- implicated in various physiological processes including:

- regulation of neuroendocrine secretion

- circadian rhythms

- appetite

- reproductive behaviour

- sympathetic cardiovascular control

and colocalises to neurons with noradrenaline. ${ }^{8}$ In contrast, in our patient neuropeptide $Y$ was concentrated in vascular areas within the tumour. Central administration of neuropeptide $\mathrm{Y}$ in the posterior hypothalamic nucleus in the rat can cause a rise in arterial blood pressure. ${ }^{4}$ Our patient had hypertension and a tumour with neuropeptide $\mathrm{Y}$ immunoreactivity, raising the possibility of an association between neuropeptide $Y$ and the central control of blood pressure in man. Any such association is likely to be complex, since in a series of papers Fuxe et al have demonstrated marked and prolonged vasodepressor and bradycardiac effects of intracisternal or intraventicularly administered neuropeptide $\mathrm{Y}$ in the rat. ${ }^{9}$ These authors found that neuropeptide $\mathrm{Y}$ mimics the central effects of $\alpha_{1}$-adrenoceptor agonists, and hypothesise that vasodepressor effects of centrally administered neuropeptide $\mathrm{Y}$ are caused by activation of high affinity neuropeptide $Y$ receptors in the nucleus tractus solitarius where baroreceptor afferents terminate. The finding in our hypertensive patient of high concentrations of neuropeptide $Y$ in a vascular tumour in the caudal part of the medulla is not necessarily counter to this. There are several possible explanations for the apparent disparity including species variation, opposing actions of neuropeptide $Y$ on closely anatomically related structures, disparate effects of neuropeptide $Y$ when released alone rather than when it is co-released with noradrenaline, and possible neuropeptide receptor down-regulation in neurons adjacent to the tumour.

7 Nathan MA, Reis D. Chronic labile hypertension produced by lesions of the nucleus tractus solitarii in the cat. Circulat Res 1977; 40: 72-81.

8 Everitt BJ, Hökfelt T, Terenius L, Tatemoto K, Mutt V, Goldstein M. Differential co-existence of neuropeptide Goldstein M. Differential co-existence of neuropeptide nervous system of the rat. Neuroscience $1984 ; 11: 443-62$.

9 Fuxe K, Härfstrand A, Agnati NF, von Euler G, Svensson 9 Fuxe K, Härfstrand A, Agnati NF, von Euler G, Svensson $T$, Fredholm B. On the role of NPY in central cardiovascular
regulation. In: Mutt V, Fuxe K, Hökfelt T, Lundberg JM, eds. Neuropeptide $Y$. New York: Raven Press, 1989; pp 201-4. 